\title{
Postoperative resource utilization and survival among liver transplant recipients with Model for End-stage Liver Disease score $\geq 40$ : A retrospective cohort study
}

\author{
Filipe S Cardoso MD ${ }^{1}$, Constantine J Karvellas MD SMำ, Norman M Kneteman MD MSc ${ }^{3}$, \\ Glenda Meeberg RN MsN4, Pedro Fidalgo MD¹, Sean M Bagshaw MD MSc${ }^{1}$
}

\begin{abstract}
FS Cardoso, CJ Karvellas, NM Kneteman, G Meeberg, P Fidalgo, SM Bagshaw. Postoperative resource utilization and survival among liver transplant recipients with Model for End-stage Liver Disease score $\geq 40$ : A retrospective cohort study. Can J Gastroenterol Hepatol 2015;29(4):185-192.
\end{abstract}

BACKGROUND: Cirrhotic patients with Model for End-stage Liver Disease (MELD) score $\geq 40$ have high risk for death without liver transplant (LT).

OBJECTIVE: To evaluate these patients' outcomes after LT.

METHODS: The present study analyzed a retrospective cohort of 519 cirrhotic adult patients who underwent LT at a single Canadian centre between 2002 and 2012. Primary exposure was severity of liver disease measured by MELD score at LT ( $\geq 40$ versus $<40$ ). Primary outcome was duration of first intensive care unit (ICU) stay after LT. Secondary outcomes were duration of first hospital stay after LT, rate of ICU readmission, re-LT and survival rates.

RESULTS: On the day of LT, $5 \%$ (28 of 519) of patients had a MELD score $\geq 40$. These patients had longer first ICU stays after LT (14 versus two days; $\mathrm{P}<0.001)$. MELD score $\geq 40$ at $\mathrm{LT}$ was independently associated with first ICU stay after LT $\geq 10$ days (OR 3.21). These patients had longer first hospital stays after LT (45 versus 18 days; $\mathrm{P}<0.001$ ); however, there was no significant difference in the rate of ICU readmission $(18 \%$ versus $22 \% ; \mathrm{P}=0.58)$ or re-LT rate $(4 \%$ versus $4 \%$; $\mathrm{P}=1.00$ ). Cumulative survival at one month, three months, one year, three years and five years was $98 \%, 96 \%, 90 \%, 79 \%$ and $72 \%$, respectively. There was no significant difference in cumulative survival stratified according to MELD score $\geq 40$ versus $<40$ at LT $(\mathrm{P}=0.59)$. CONCLUSIONS: Cirrhotic patients with MELD score $\geq 40$ at LT utilize greater postoperative health resources; however, they derive similar long-term survival benefit from LT.

Key Words: Cirrhosis; End-stage liver disease; Liver transplant; MELD
L'utilisation des ressources après l'opération et la survie des greffés du foie ayant un score MELD de 40 ou plus : une étude rétrospective de cohorte

HISTORIQUE : Les patients cirrhotiques ayant un score MELD (acronyme anglais de modèle de maladie hépatique en phase terminale) de 40 ou plus risquent fort de mourir sans avoir reçu de transplantation hépatique $(\mathrm{TH})$.

OBJECTIF : Évaluer les résultats de ces patients après une TH.

MÉTHODOLOGIE : La présente étude portait sur une cohorte de 519 patients cirrhotiques adultes qui ont subi une TH dans un seul centre canadien entre 2002 et 2012. L'exposition primaire était la gravité de la maladie hépatique mesurée par le score MELD à la TH (40 ou plus par rapport à moins de 40). Le résultat primaire était la durée du premier séjour en soins intensifs (USI) après la $\mathrm{TH}$, le taux de réadmissions à l'USI, une nouvelle $\mathrm{TH}$ et les taux de survie.

RÉSULTATS : Le jour de la TH, 5 \% des patients (28 sur 519) avaient un score MELD de 40 ou plus. Ces patients séjournaient plus longtemps à l'USI après la TH (14 jours par rapport à deux; $\mathrm{P}<0,001)$. Leur score MELD de 40 ou plus à la TH s'associait de manière indépendante à un premier séjour à l'USI de dix jours ou plus après la TH (RC 3,21). Le premier séjour hospitalier de ces patients était plus long après la TH (45 jours par rapport à $18 ; \mathrm{P}<0,001$ ), mais il n'y avait pas de différence significative dans le taux de réadmission à l'USI (18\% par rapport à $22 \% ; \mathrm{P}=0,58)$ ou de nouvelle TH (4 \% par rapport à $4 \%$; $\mathrm{P}=1,00)$. La survie cumulative au bout d'un mois, de trois mois, d'un an, de trois ans et de cinq ans s'élevait à $98 \%, 96 \%, 90 \%, 79 \%$ et $72 \%$, respectivement. Il n'y avait pas de différence significative dans la survie cumulative stratifiée selon le score MELD de 40 ou plus par rapport à celui de moins de 40 à la $T H(P=0,59)$. CONCLUSIONS : Les patients cirrhotiques ayant un score MELD de 40 ou plus à la TH utilisaient plus de ressources de santé après l'opération, mais tiraient des bienfaits similaires de la TH à long terme sur le plan de la survie.
The Model for End-stage Liver Disease (MELD), a marker of chronic 1 liver disease severity based on the patient's serum bilirubin and creatinine levels, and international normalized ratio (1), has proven to be an accurate predictor of wait list for liver transplant (LT) threemonth mortality (2).

Adoption of MELD to select and prioritize patients on the wait list for LT has contributed to a reduction in the number of patients waiting for LT, shorter wait times, an increase in the number of LT procedures and lower mortality (3).

Despite the continuous character of MELD, transplant authorities have decided to restrict its score to a maximum of 40 . However, recent data have shown that patients with a MELD score $\geq 40$ have higher wait list mortality than candidates with a lower MELD score $(4,5)$.
While patients with end-stage liver disease and a high MELD score represent considerable resource expenditure for the health system, especially if transplanted, their outcomes have been reported to be acceptable (6-8)

We hypothesized that patients with a MELD score $\geq 40$ at LT would consume greater health resources post-LT, but would achieve similar short- and long-term survival rates. Accordingly, our primary objective was to determine whether patients with a biochemical MELD score $\geq 40$ at LT would have a longer duration of first intensive care unit (ICU) stay after LT. Our secondary objectives were to evaluate these patients' duration of first hospital stay after LT, rate of ICU readmission, re-LT rate, and one-month, three-month, one-year, three-year and five-year survival rates.

${ }^{1}$ Division of Critical Care Medicine; ${ }^{2}$ Division of Gastroenterology, Department of Medicine, Faculty of Medicine and Dentistry; ${ }^{3}$ Division of Transplantation, Department of Surgery, University of Alberta; ${ }^{4}$ Liver Transplant Program, Alberta Health Services, Edmonton, Alberta

Correspondence: Dr Constantine J Karvellas, Division of Critical Care Medicine, Division of Hepatology, 1-40 Zeidler Ledcor Building, University of Alberta, 130 University Drive, Edmonton, Alberta T6G 2X8. Telephone 780-492-4390, fax 780-492-5643,

e-mail dean.karvellas@ualberta.ca

Received for publication April 16, 2014. Accepted February 12, 2015 


\section{METHODS}

The present study adhered to the STROBE statement for observational studies (9). The local ethics committee approved the present study before commencement. The requirement for individual informed consent was waived.

\section{Design, setting and participants}

The present analysis was a single-centre, retrospective cohort study, which included all adult ( $\geq 18$ years of age) cirrhotic patients who underwent LT at a Canadian transplant centre (University of Alberta Hospital [Edmonton, Alberta]) between January 1, 2002 and June 30, 2012. Patients were excluded if: they had concomitant transplant with another organ (eg, liver, kidney); their primary diagnosis was acute liver failure; or they were lost to follow-up.

\section{Operational definitions}

Cirrhosis was defined as bridging fibrosis on previous liver biopsy or a composite of clinical signs and findings provided by laboratory test results, endoscopy and radiological imaging (10).

Complications of cirrhosis included infection, variceal bleeding, hepatic encephalopathy, hepatorenal syndrome and hepatopulmonary syndrome. Although infection is not a specific complication of cirrhosis, it was considered as such due to its high prevalence and potential to alter disease course, being a common cause of acute decompensation and increased mortality (11). This definition included spontaneous bacterial peritonitis, bloodstream infection, urinary tract infection and pneumonia. Variceal bleeding was defined as any confirmed episode of acute bleeding originating from esophageal or gastric varices due to portal hypertension (12). Hepatic encephalopathy was defined as any acute confusional state in a patient with underlying liver disease, after excluding any potentially confounding metabolic, infectious or neurological disorders (13). Hepatorenal syndrome was defined as acute kidney injury in a patient with advanced liver disease in the absence of an identifiable cause based on the most recent criteria of the European Association for the Study of the Liver (14). Hepatopulmonary syndrome was defined as an oxygenation defect caused by pulmonary vascular dilation in the setting of portal hypertension, with the diagnosis being made by contrast-enhanced transthoracic echocardiography (15).

All MELD scores were calculated according to the United Network for Organ Sharing recommendations (16), without adjusting for serum sodium level or standardized exception points (17).

\section{Variables}

The primary exposure was the severity of end-stage liver disease measured by biochemical MELD score at LT $(\geq 40$ versus $<40$ ). The primary outcome was the duration of first ICU stay after LT. A prolonged first ICU stay following LT was defined as $\geq 10$ days based on previous literature $(8,18)$. The secondary outcomes were the duration of first hospital stay after LT, rate of ICU readmission, re-LT rate, and onemonth, three-month, one-year, three-year and five-year patient cumulative survival rates.

\section{Data collection}

The LT program at the University of Alberta Hospital started in 1989 and, since 1995, has maintained a dedicated computerized database of all cases using the Organ Transplant Tracking Record (HKS Medical Information Systems, USA).

Eligible patients were initially identified using the Organ Transplant Tracking Record. Data regarding patients' age, sex, race, body mass index, etiology of liver disease and its complications, comorbidities, laboratory parameters, the need for pretransplant ICU admission, severity aggregate scores (Sequential Organ Failure Assessment, Child-Turcotte-Pugh and MELD), time between listing for and receipt of LT, Donor Risk Index parameters (19), operative requirements of red blood cells and platelets, and outcomes were extracted from that database and from patients' medical records.

\section{Statistical analysis}

Statistical analysis was performed using SPSS version 20.0 (IBM Corporation, USA). Categorical variables were presented as frequencies (percentages) and continuous variables as mean $\pm \mathrm{SD}$, if normally distributed, or median (interquartile range [IQR]) if non-normally distributed. In the event of missing values, data were not replaced or estimated.

Univariable analysis of outcomes was performed using $\chi^{2}$ or Fisher's exact test ( $<5$ events) for categorical variables, and Student's $t$ test (parametric) or Mann-Whitney test (nonparametric) for continuous variables; $\mathrm{P}<0.05$ was considered to be statistically significant for all comparisons.

Crude survival analysis was performed using the Kaplan-Meier estimator (with Breslow test) and adjusted survival analysis with Cox proportional-hazards regression. In this context, potentially confounding factors were selected based on previous literature (20) and clinical rationale.

Logistic regression was performed to study the effect of a MELD score $\geq 40$ at LT on the probability of experiencing a prolonged first ICU stay following LT, after adjustment for other patients', donors' and perioperative covariates. Variables initially included in the model were selected based on the following three features: minimum frequency of $85 \%$ of the total number of cases under analysis (21); $\mathrm{P}<0.15$ on univariable analysis; and clinical rationale. A backward stepwise selection of variables was performed to build the final models. Potentially collinear variables were excluded. Models' goodness of fit and discrimination were assessed using the $\chi^{2}$ statistic (with correspondent degrees of freedom) and the area under ROC curve, respectively.

\section{RESULTS}

Patients', donors' and perioperative characteristics

Of the 603 LT procedures performed at the University of Alberta Hospital during the study period, 519 met the eligibility criteria. Median follow-up time for the entire cohort was 3.6 years (IQR 1.5 to 6.4 years).

Patients' pre-LT characteristics for the entire cohort and stratified according to MELD score categories at LT $(\geq 40$ versus $<40)$ are shown in Table 1 .

On the day of LT, median MELD score was 15 (IQR 11 to 23); at that same time, $5 \%$ ( 28 of 519 ) of patients had a MELD score $\geq 40$, with a correspondent median score of 43 (IQR 41 to 46). The proportions of these patients for the periods 2002 to 2006 and 2007 to 2012 were similar ( $4 \%$ versus $7 \% ; \mathrm{P}=0.20$ ). While median age ( 54 versus 53 years) and male sex proportion (68\% versus 68\%) were similar between the two MELD score categories ( $\mathrm{P}>0.50$ for both comparisons), patients with a MELD score $\geq 40$ at LT had a marginally significant greater median body mass index $\left(26 \mathrm{~kg} / \mathrm{m}^{2}\right.$ versus $\left.25 \mathrm{~kg} / \mathrm{m}^{2} ; \mathrm{P}=0.047\right)$.

The most common indications for LT were hepatitis C (32\% versus $23 \%)$ and hepatic malignancy (11\% versus $22 \%)$, and their proportions were similar between the two MELD score categories $(\mathrm{P}>0.20$ for both comparisons). Patients with a MELD score $\geq 40$ at LT were more likely to have infection ( $67 \%$ versus $39 \%$; $=0.005)$, hepatic encephalopathy ( $89 \%$ versus $59 \% ; \mathrm{P}=0.001)$ and hepatorenal syndrome $(54 \%$ versus $14 \% ; \mathrm{P}<0.001)$ before $\mathrm{LT}$. ICU admission before LT was required for $13 \%$ (69 of 519) of patients and occurred more commonly in patients with a MELD score $\geq 40$ at transplant ( $82 \%$ versus $9 \%$; $\mathrm{P}<0.001)$. Organ support was necessary for the majority of patients in the ICU: mechanical ventilation in 76\% (34 of 45); vasopressors in $71 \%$ (32 of 45); and renal replacement therapy in 69\% (31 of 45). Among patients in ICU, there were nonsignificant trends toward greater use of vasopressors ( $88 \%$ versus $62 \%$ ) and renal replacement therapy ( $88 \%$ versus $59 \%$ ) in those with a MELD score $\geq 40$ at transplant ( $\mathrm{P}=0.09$ for both comparisons). On the day of LT, patients in ICU had a mean $( \pm$ SD) Sequential Organ Failure Assessment score of $16 \pm 4$, which was similar for the two MELD score categories (17 versus $16 ; \mathrm{P}=0.14)$.

Donors' and perioperative characteristics for the entire cohort and stratified according to MELD score categories at LT $(\geq 40$ versus $<40)$ are 
TABLE 1

Analysis of patients' pre-liver transplant (LT) characteristics for the entire cohort and according to Model for End-stage Liver Disease (MELD) score $(\geq 40$ versus $<40)$ categories at LT

\begin{tabular}{|c|c|c|c|c|}
\hline \multirow[b]{2}{*}{ Characteristic } & \multirow[b]{2}{*}{ Total } & \multicolumn{2}{|c|}{ MELD score } & \multirow[b]{2}{*}{$\mathbf{P}$} \\
\hline & & $<40(n=491)$ & $\geq 40(n=28)$ & \\
\hline \multicolumn{5}{|l|}{ Demographics } \\
\hline Age, years, median (IQR) $(n=519)$ & $54(48-59)$ & $54(48-59)$ & $53(48-59)$ & 0.57 \\
\hline Race (Caucasian) , n (\%) (n=515) & $441(86)$ & $419 / 487(86)$ & $22 / 28(79)$ & 0.27 \\
\hline Body mass index, $\mathrm{kg} / \mathrm{m}^{2}$, median (IQR) $(\mathrm{n}=517)$ & $25(22-28)$ & $25(22-28)$ & $26(23-31)$ & 0.047 \\
\hline \multicolumn{5}{|l|}{ Indication for LT, n (\%) ( $\mathrm{n}=519)$} \\
\hline Hepatitis B & $13(3)$ & $10 / 491(2)$ & $3 / 28(11)$ & 0.028 \\
\hline Hepatic malignancy & $109(21)$ & 106/491 (22) & $3 / 28(11)$ & 0.23 \\
\hline Primary biliary cirrhosis or primary sclerosing cholangitis & $96(18)$ & 90/491 (18) & $6 / 28(21)$ & 0.68 \\
\hline Alcohol & $70(14)$ & $68 / 491(14)$ & $2 / 28(7)$ & 0.41 \\
\hline Nonalcoholic steatohepatitis or cryptogenic & $41(8)$ & $39 / 491(8)$ & $2 / 28(7)$ & 1.00 \\
\hline Autoimmune & $20(4)$ & $20 / 491(4)$ & $0 / 28(0)$ & 0.62 \\
\hline Variceal bleeding $(n=517)$ & $235(45)$ & $220 / 489(45)$ & $15 / 28(54)$ & 0.38 \\
\hline Hepatic encephalopathy $(n=519)$ & $312(60)$ & $287 / 491(59)$ & $25 / 28(89)$ & 0.001 \\
\hline Grades 3 to 4 & $90(17)$ & $73 / 491(15)$ & $17 / 28(61)$ & $<0.001$ \\
\hline Hepatorenal syndrome $(n=456)$ & $75(16)$ & $61 / 430(14)$ & $14 / 26(54)$ & $<0.001$ \\
\hline Hepatopulmonary syndrome $(n=454)$ & $12(3)$ & $12 / 428(3)$ & $0 / 26(0)$ & 1.00 \\
\hline \multicolumn{5}{|l|}{ Comorbidities, n (\%) } \\
\hline Coronary artery disease $(n=519)$ & $24(5)$ & $24 / 491(5)$ & $0 / 28(0)$ & 0.63 \\
\hline Chronic obstructive pulmonary disease $(n=519)$ & $22(4)$ & $22 / 491(5)$ & $0 / 28(0)$ & 0.62 \\
\hline Diabetes mellitus $(n=519)$ & $110(21)$ & $103 / 491(21)$ & $7 / 28(25)$ & 0.61 \\
\hline Chronic kidney diease (GFR <60 mL/min) $(\mathrm{n}=374)$ & $78(21)$ & $70 / 351(20)$ & $8 / 23(35)$ & 0.09 \\
\hline \multicolumn{5}{|l|}{ Laboratory parameters (day of LT) } \\
\hline Intensive care unit stay before $L T, n(\%)(n=519)$ & $69(13)$ & $46 / 491(9)$ & $23 / 28(82)$ & $<0.001$ \\
\hline Mechanical ventilation ${ }^{\dagger}(n=45)$ & $34(76)$ & $23 / 29(79)$ & $11 / 16(69)$ & 0.43 \\
\hline Vasopressors $^{\dagger}(\mathrm{n}=45)$ & $32(71)$ & $18 / 29(62)$ & $14 / 16(88)$ & 0.09 \\
\hline Renal replacement therapy ${ }^{\dagger}(n=45)$ & $31(69)$ & $17 / 29(59)$ & $14 / 16(88)$ & 0.09 \\
\hline \multicolumn{5}{|l|}{ Severity aggregate scores (day of LT) } \\
\hline Sequential Organ Failure Assessment ${ }^{* \dagger}$, mean \pm SD $(n=45)$ & $16 \pm 4$ & $16 \pm 4$ & $17 \pm 3$ & 0.14 \\
\hline Child-Turcotte-Pugh, median (IQR) $(n=519)$ & $10(8-12)$ & $9(7-12)$ & $13(12-13)$ & $<0.001$ \\
\hline
\end{tabular}

*Normal distribution; ${ }^{\dagger}$ Data available for 45 of 69 patients. IQR Interquartile range; GFR Glomerular filtration rate

presented in Appendix 1. Median time between listing for and receipt of LT was significantly lower for patients with a MELD score $\geq 40$ at LT (1.3 versus 6.2 months; $\mathrm{P}<0.001$ ). Due to their liver disease severity, these patients received an organ from a national source more often (64\% versus 36\%; P=0.003). The median Donor Risk Index score was similar for the two MELD score categories (1.5 versus $1.4 ; \mathrm{P}=0.19$ ).

\section{Primary outcome}

Overall, median length of first ICU stay following LT was two days (IQR one to six days) days. Patients with a MELD score $\geq 40$ at LT had significantly greater median length of first ICU stay after LT (14 days [IQR five to 24 days) versus two days (IQR one to five days); $\mathrm{P}<0.001$ (Figure 1).
Factors associated with a prolonged first ICU stay after LT Univariable analysis for patients', donors' and perioperative characteristics stratified according to the duration of first ICU stay after LT is presented in Table 2.

The predicted probability of experiencing a prolonged ICU stay after LT was associated with the continuous MELD score at LT (Figure 2). On unadjusted analysis, a MELD score $\geq 40$ at LT was significantly associated with a length of first ICU stay after LT $\geq 10$ days (OR 6.73 [95\% CI 3.07 to 14.7]; $\mathrm{P}<0.001$ ) (Table 3). After adjusting for demographics (age and sex), pre-LT complications of cirrhosis (high-grade [3 to 4] hepatic encephalopathy, hepatorenal syndrome and hepatopulmonary syndrome), ICU stay before LT, standardized quality assessment of the liver received (Donor Risk Index) and the volume of red blood cells used during 
TABLE 2

Analysis of patients', donors' and perioperative characteristics for the entire cohort and according to duration of the first intensive care unit stay after liver transplant ( $\geq 10$ days versus $<10$ days)

\begin{tabular}{|c|c|c|c|}
\hline \multirow[b]{2}{*}{ Characteristic } & \multicolumn{2}{|c|}{ Intensive care unit stay } & \multirow[b]{2}{*}{$\mathbf{P}$} \\
\hline & $<10$ days $(n=427)$ & $\geq 10$ days $(n=86)$ & \\
\hline \multicolumn{4}{|l|}{ Demographics } \\
\hline Age, years, median (IQR) $(n=519)$ & $54(48-59)$ & $54(50-59)$ & 0.42 \\
\hline Race (Caucasian), $n / n(\%)(n=515)$ & $369 / 424(87)$ & $68 / 85(80)$ & 0.09 \\
\hline Body mass index, $\mathrm{kg} / \mathrm{m}^{2}$, median (IQR) $(\mathrm{n}=517)$ & $24(22-28)$ & $25(23-30)$ & 0.045 \\
\hline \multicolumn{4}{|l|}{ Indication for liver transplant, $n / n(\%)(n=519)$} \\
\hline Hepatitis B & $12 / 427(3)$ & $1 / 86(1)$ & 0.71 \\
\hline Hepatic malignancy & $87 / 427(20)$ & $19 / 86(22)$ & 0.72 \\
\hline Primary biliary cirrhosis or primary sclerosing cholangitis & $79 / 427(19)$ & $16 / 86(19)$ & 0.98 \\
\hline Alcohol & $56 / 427(13)$ & $12 / 86(14)$ & 0.83 \\
\hline \multicolumn{4}{|l|}{ Complications of cirrhosis, $n / n(\%)$} \\
\hline Infection $(n=465)$ & 150/382 (39) & $39 / 77(51)$ & 0.06 \\
\hline Hepatorenal syndrome $(n=456)$ & $54 / 372(15)$ & $21 / 78(27)$ & 0.008 \\
\hline Hepatopulmonary syndrome $(n=454)$ & $6 / 370(2)$ & $6 / 78(17)$ & 0.003 \\
\hline \multicolumn{4}{|l|}{ Comorbidities, $\mathrm{n} / \mathrm{n}(\%)$} \\
\hline Coronary artery disease $(n=519)$ & $20 / 427(5)$ & $4 / 86(5)$ & 1.00 \\
\hline Chronic obstructive pulmonary disease $(n=519)$ & $19 / 427(4)$ & $3 / 86(4)$ & 1.00 \\
\hline Diabetes mellitus $(n=519)$ & $93 / 427(22)$ & $17 / 86(20)$ & 0.68 \\
\hline Chrnic kidney disease (GFR <60 mL/min) $(n=374)$ & $60 / 300(20)$ & $16 / 69(23)$ & 0.56 \\
\hline \multicolumn{4}{|l|}{ Laboratory parameters (day of liver transplant) } \\
\hline Hemoglobin*, g/L, mean \pm SD $(n=188)$ & $101 \pm 20$ & $94 \pm 19$ & 0.037 \\
\hline International normalized ratio, median (IQR) $(\mathrm{n}=519)$ & $1.3(1.2-1.7)$ & $1.6(1.2-2.8)$ & $<0.001$ \\
\hline Albumin, g/L, median (IQR) $(\mathrm{n}=486)$ & $34(30-39)$ & $36(31-41)$ & 0.08 \\
\hline Renal replacement therapy ${ }^{\dagger}(n=45)$ & $11 / 22(50)$ & $20 / 23(87)$ & 0.011 \\
\hline \multicolumn{4}{|l|}{ Severity aggregate scores (day of liver transplant) } \\
\hline Sequential Organ Failure Assessment ${ }^{\star \dagger}$, mean \pm SD $(n=45)$ & $14 \pm 3$ & $18 \pm 3$ & 0.001 \\
\hline Child-Turcotte-Pugh, median (IQR) $(n=519)$ & $9(7-11)$ & $12(9-13)$ & $<0.001$ \\
\hline Model for End-stage Liver Disease score $(n=519)$ & $15(10-22)$ & $22(11-35)$ & $<0.001$ \\
\hline Donor risk index $(n=455)$ & $1.4(1.2-1.7)$ & $1.5(1.2-1.7)$ & 0.78 \\
\hline Red blood cells in operating room, units, median (IQR) $(n=519)$ & $2(0-5)$ & $5(0-12)$ & $<0.001$ \\
\hline Platelets in operating room, units, median (IQR) $(n=519)$ & $0(0-4)$ & $2(0-7)$ & $<0.001$ \\
\hline
\end{tabular}

${ }^{*}$ Normal distribution; ${ }^{\dagger}$ Data available for 45 of 69 patients. IQR Interquartile range; GFR Glomerular filtration rate

the LT surgery, the OR for this association remained significant $(\mathrm{OR}$ 3.21 [ $95 \%$ CI 1.12 to 9.20]; $\mathrm{P}=0.030$ ).

In the same multivariable analysis, other factors that showed a significant association with a prolonged first ICU stay after LT were high-grade hepatic encephalopathy (OR 2.29 [95\% CI 1.14 to 4.60]; $\mathrm{P}=0.020$ ), hepatopulmonary syndrome (OR 4.86 [95\% CI 1.23 to 19.2]; $\mathrm{P}=0.024$ ) and preoperative ICU admission (OR 2.42 [95\% CI 1.02 to 5.71]; $\mathrm{P}=0.044$ ) before LT. Additionally, transfusion of $\geq 5$ units of red blood cells during the LT surgery showed a nonsignificant trend toward a higher likelihood of a prolonged first ICU stay after LT (OR 1.75 [95\% CI 0.97 to 3.16]; $\mathrm{P}=0.06$ )
Secondary outcomes

Overall, the median length of first hospital stay following LT was 19 days (IQR 12 to 36 days). Patients with a MELD score $\geq 40$ at LT experienced significantly greater median length of first hospital stay after LT (45 days [IQR 26 to 66 days]) versus 18 days [IQR 11 to 34 days]; $\mathrm{P}<0.001$ ) (Figure 1).

For the entire follow-up period, the rate of ICU readmission was $22 \%$ (113 of 513 ). Of all ICU readmissions, 36\% (41 of 113 ) represented at least a second readmission. Overall, median time to first ICU readmission was 16 days (IQR five to 346 days). The rate of ICU readmission was similar for the two MELD score categories (18\% [five of 28] versus $22 \%$ [108 of 485]; $\mathrm{P}=0.58$ ). 
Liver transplant outcomes of high MELD score patients

TABLE 3

Logistic regression analysis: variables associated with a length of first intensive care unit stay after liver transplant (LT) $\geq 10$ days

\begin{tabular}{|c|c|c|c|c|c|c|}
\hline \multirow[b]{2}{*}{ Variable } & \multicolumn{2}{|c|}{ Unadjusted } & \multicolumn{2}{|l|}{ Model 1} & \multicolumn{2}{|l|}{ Model 2} \\
\hline & OR $(95 \% \mathrm{CI})$ & $\mathbf{P}$ & OR $(95 \% \mathrm{Cl})$ & $\mathbf{P}$ & OR $(95 \% \mathrm{Cl})$ & $\mathbf{P}$ \\
\hline Age, years & $1.01(0.99-1.04)$ & 0.37 & $1.01(0.99-1.04)$ & 0.30 & $1.01(0.98-1.04)$ & 0.61 \\
\hline Male sex & $0.91(0.56-1.49)$ & 0.70 & $0.90(0.54-1.50)$ & 0.69 & $0.85(0.46-1.56)$ & 0.59 \\
\hline Biochemical MELD score at LT $(\geq 40)$ & $6.73(3.07-14.7)$ & $<0.001$ & $6.86(3.12-15.1)$ & $<0.001$ & $3.21(1.12-9.20)$ & 0.030 \\
\hline Hepatic encephalopathy (grades 3 to 4 ) & $4.33(2.59-7.25)$ & $<0.001$ & & & $2.29(1.14-4.60)$ & 0.020 \\
\hline Hepatorenal syndrome & $2.17(1.22-3.87)$ & 0.009 & & & $0.81(0.37-1.74)$ & 0.58 \\
\hline Hepatopulmonary syndrome & $5.06(1.59-16.1)$ & 0.006 & & & $4.86(1.23-19.2)$ & 0.024 \\
\hline Intensive care unit admission before LT & $5.33(3.07-9.26)$ & $<0.001$ & & & $2.42(1.02-5.71)$ & 0.044 \\
\hline Donor risk index & $1.08(0.57-2.07)$ & 0.81 & & & $0.76(0.36-1.60)$ & 0.46 \\
\hline Red blood cells in operating room ( $\geq 5$ units) & $3.08(1.92-4.96)$ & $<0.001$ & & & $1.75(0.97-3.16)$ & 0.06 \\
\hline
\end{tabular}

Model 1 goodness of fit ( $n=513$ ): $X^{2} 22$ (degrees of freedom ([Df], 3); P<0.001; Area under the ROC curve (AUROC) 0.61 (95\% CI 0.54 to 0.67). Model 2 goodness of fit (n=399): $X^{2} 49$ (Df, 9); $P<0.001$; AUROC 0.75 (95\% Cl 0.68 to 0.81). MELD Model for End-stage Liver Disease

For the entire period of follow-up, the re-LT rate was $4 \%$ (18 of 519). Causes of re-LT were hepatic artery thrombosis (56\% [10 of 18]), primary nonfunction (17\% [three of 18]), acute rejection (6\% [one of $18]$ ), chronic rejection ( $6 \%$ [one of 18]) and others (17\% [three of 18]). The re-LT rate was similar for the two MELD score categories (4\% [one of 28] versus 4\% [17 of 491]; $\mathrm{P}=1.00$ ).

During the study period, 139 deaths occurred. Causes of death were recurrence of underlying liver disease (32\% [45 of 139]), sepsis ( $24 \%$ [33 of 139]), cardiovascular events (18\% [25 of 139]), de novo malignancy (12\% [16 of 139]), chronic rejection (4\% [five of 139]) and others (11\% [15 of 139$])$.

Kaplan-Meier cumulative survival at one month, three months, one year, three years and five years was $98 \%, 96 \%, 90 \%, 79 \%$ and $72 \%$, respectively. Kaplan-Meier curves were similar for the two MELD score categories ( $\mathrm{P}=0.59$ [Figure 3]). After adjusting for confounding factors, including age, sex, etiology of liver disease (hepatitis $\mathrm{C}$ versus other) and ICU admission before LT, a MELD score $\geq 40$ at LT was not significantly associated with survival (HR 0.76 [95\% CI 0.33 to 1.73]; $\mathrm{P}=0.51$ ). Advanced age was the only factor significantly associated with worse survival after LT (HR 1.03 per incremental year [95\% CI 1.01 to 1.06 ]; $\mathrm{P}=0.002$ (model not shown [ $=519$ ]: $\chi^{2} 25$ [degrees of freedom 6]; $\mathrm{P}<0.001$ ).

\section{DISCUSSION}

The purpose of the present study was to characterize post-LT outcomes of patients with end-stage liver disease and a MELD score $\geq 40$ at LT.

\section{Key results}

In a large single-centre cohort of adult cirrhotic patients who underwent LT, we found that patients with a biochemical MELD score $\geq 40$ at LT had significantly greater length of first ICU and hospital stays following LT, but similar short- and long-term survival. We also found that a biochemical MELD score $\geq 40$ at LT, high-grade hepatic encephalopathy, hepatopulmonary syndrome and ICU admission before LT, were all independently associated with a length of first ICU stay after LT $\geq 10$ days.

\section{Comparison with previous studies}

Our findings that a MELD score $\geq 40$ at LT was significantly associated with a prolonged first ICU stay after LT, but not with survival, are consistent with results from previous studies. Oberkofler et al (8) found that a MELD score $>23$ was significantly associated with a length of ICU stay after transplant $>10$ days, but not with survival. Conclusions of this study may not be readily comparable with ours because they used the MELD corrected for exceptions (hepatocellular carcinoma and hepatopulmonary syndrome), instead of the biochemical MELD, which resulted in greater median MELD scores (19 [IQR eight to 40]) and, possibly, overestimation of liver disease severity. Similarly to our study, Alexopoulos et al (7) reported, for patients with

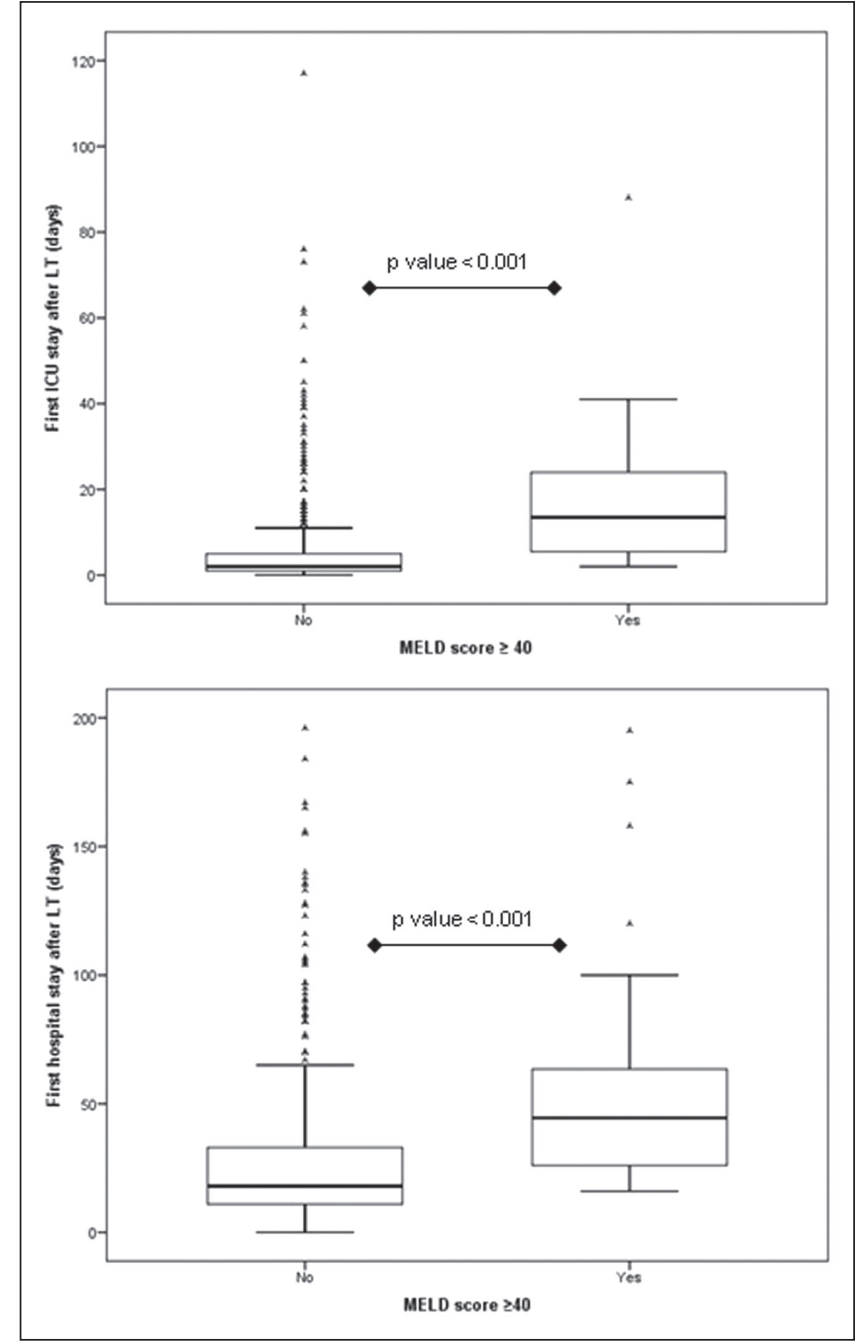

Figure 1) Median length of first intensive care unit and hospital stays according to biochemical Model for End-stage Liver Disease (MELD) score categories $(\geq 40$ versus $<40)$ at liver transplant (LT)

an unspecified MELD score $\geq 40$ at LT, Kaplan-Meier cumulative survival at one year and three years of $89 \%$ and $77 \%$, respectively. In contrast to our study, they included patients receiving both LT and kidney transplants, and excluded those who received a split graft; however, outcomes for these patients have been reported to be similar to those of whole liver-only recipients $(22,23)$. Further evidence 


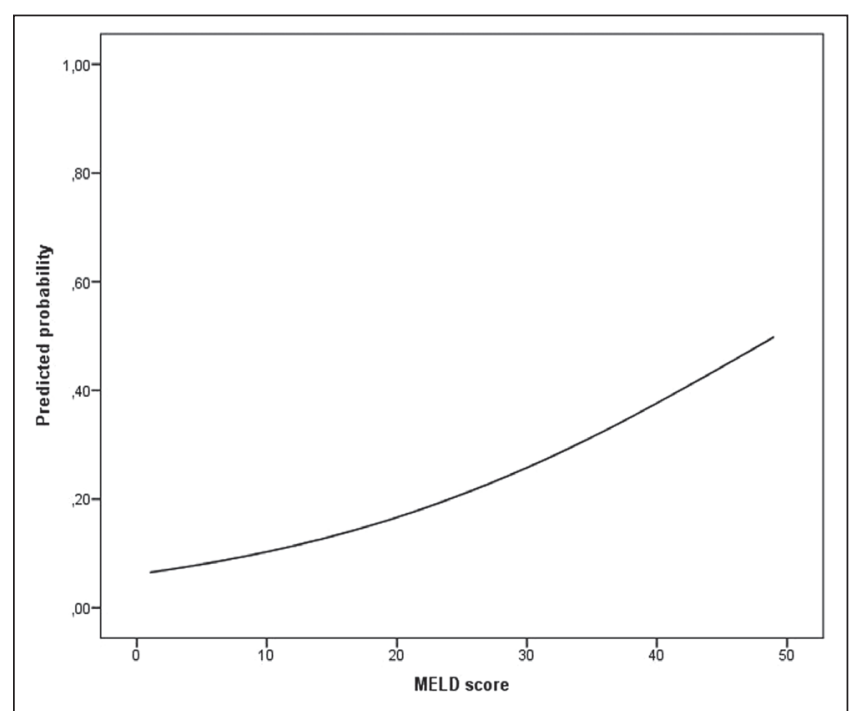

Figure 2) Unadjusted predicted probabilities of a length of first intensive care unit stay after liver transplant $\geq 10$ days according to continuous biochemical Model for End-stage Liver Disease (MELD) score at liver transplant

regarding the absence of a significant association between MELD score and survival after LT was provided by Sharma et al (5), who found that cirrhotic patients with a biochemical MELD score $\geq 40$ at listing had a post-LT survival similar to transplant recipients for fulminant hepatic failure, the highest status group of patients for liver allocation. Overall, these results consistently indicate that patients with a MELD score $\geq 40$ at LT are at higher risk for a longer duration of the first ICU stay postoperatively; however, their short- and long-term survival is expected to be similar to other LT recipients.

The significant association of pre-LT high-grade hepatic encephalopathy with a prolonged first ICU stay after LT found in our cohort has not been reported in the literature. In fact, pre-LT hepatic encephalopathy has been associated with post-LT neurocognitive changes $(24,25)$, but its role as a predictor of outcomes after LT has not been well characterized. In a study involving cirrhotic patients admitted to the ICU for high-grade hepatic encephalopathy, but without receiving LT, Fichet et al (26) reported a median length of stay of six days (IQR two to 10 days) and an ICU mortality (35\% [25 of 71]) greater than what has been reported for other cirrhotic patients admitted to the ICU.

Although we found pre-LT hepatopulmonary syndrome to be significantly associated with a prolonged first ICU stay after LT, possibly in the context of these patients' high dependence on oxygen, outcomes of hepatopulmonary syndrome reported in the literature are controversial, with some studies suggesting acceptable outcomes $(27,28)$ and others suggesting that these patients experience poor outcomes after LT $(29,30)$.

The association between ICU admission before LT and the duration of hospital stay after transplant has been studied. Smith et al (31) found that ICU admission before LT was independently associated with a longer hospital stay after transplant; however, this study did not specifically evaluate the utilization of ICU resources postoperatively. Oberkofler et al (8) did not find any significant association between ICU admission before LT and a length of ICU stay after LT $>10$ days.

While we found a nonsignificant trend between a consumption of $\geq 5$ units of red blood cells during transplant surgery and a prolonged first ICU stay after LT, Oberkofler et al (8) reported that patients who underwent LT and were transfused with $>7$ units of red blood cells during the procedure had a significantly higher likelihood of experiencing a length of ICU stay after LT of $>10$ days.

Overall, these results suggest that patients with one or more factors found to independently increase the risk for a prolonged first ICU stay

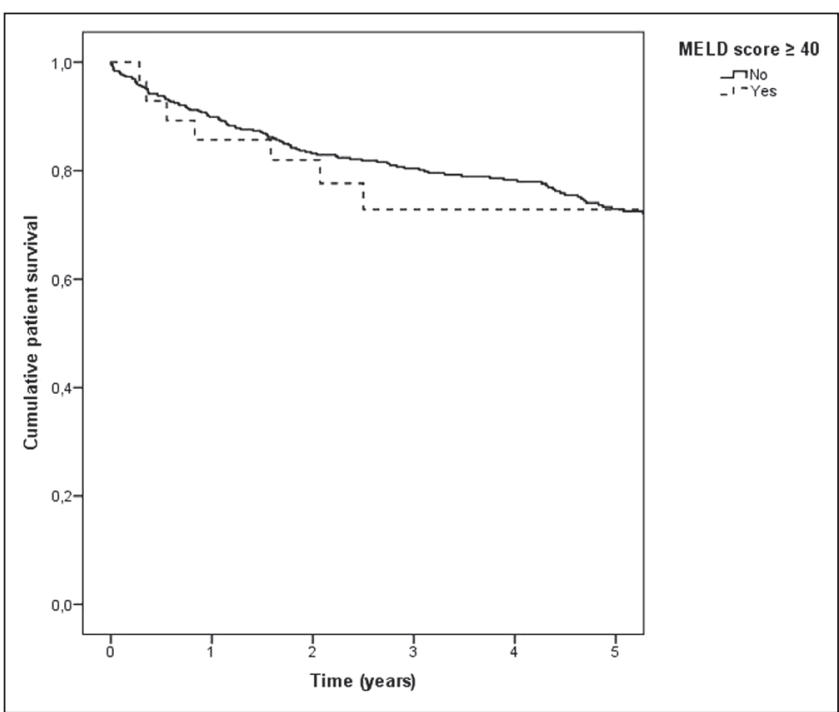

Figure 3) Kaplan-Meier patient survival curve for biochemical Model for End-stage Liver Disease (MELD) score categories $(\geq 40$ versus $<40)$ at liver transplant $(P=0.59)$

after LT should be expected to consume a greater volume of hospital resources; therefore, specific institutional policies should be developed to improve the efficiency of care provided to them.

\section{Study limitations}

The results of the present study need to be considered in the context of the following limitations. First, it was a retrospective analysis of prospectively collected data from a single transplant centre and may be prone to selection bias. Second, individual transplant centres, especially from different countries, have diverse groups of patients and practices regarding enlistment for transplant, allocation of organs, and medical and surgical management strategies; therefore, results may, in part, reflect those specific realities. Despite these limitations, our study was one of the few to characterize the health resource utilization, and shortand long-term outcomes of cirrhotic patients with a MELD score $\geq 40$ at LT. In future studies, an effort should be made to standardize the most valuable markers of post-LT morbidity and survival to further help decision-making on organ allocation and peri-LT care.

\section{CONCLUSIONS}

While cirrhotic patients with a MELD score $\geq 40$ at LT experienced significantly greater length of first ICU and hospital stays after LT, they derived similar long-term survival benefit. Despite representing a higher burden of care and costs for the health system, these patients seemed to similarly benefit from LT.

ACKNOWLEDGEMENTS: Dr Bagshaw is supported by a Canada Research Chair in Critical Care Nephrology and Clinical Investigator Award from Alberta Innovates - Health Solutions. Drs Cardoso and Fidalgo are supported by an unrestricted educational grant donated by Gambro Inc.

DISCLOSURES: The authors have no financial disclosures or conflicts of interest to declare.

CONSENT: Given that this was a retrospective study, the Institutional Review Board at the University of Alberta waved the requirement for informed consent. While this was a retrospective study and no patients were in contact with study investigators, ethical standards were in accordance with the Helsinki Declaration of 1975, as revised in 2000 and 2008. 
Liver transplant outcomes of high MELD score patients

\section{APPENDIX 1}

Analysis of donors' and perioperative characteristics for the entire cohort and according to Model for End-stage Liver Disease (MELD) score ( $\geq 40$ versus $<40$ ) categories at liver transplant (LT)

\begin{tabular}{|c|c|c|c|c|}
\hline & \multirow[b]{2}{*}{ Total $(n=519)$} & \multicolumn{2}{|c|}{ MELD score } & \multirow[b]{2}{*}{$\mathbf{P}$} \\
\hline & & $<40(n=491)$ & $\geq 40(n=28)$ & \\
\hline Time between listing for and receipt of LT, months, median (IQR) $(n=519)$ & $5.6(1.6-12.6)$ & $6.2(1.8-13.2)$ & $1.3(0.4-4.1)$ & $<0.001$ \\
\hline Donor risk index, median (IQR) $(n=455)$ & $1.4(1.2-1.7)$ & $1.4(1.2-1.7)$ & $1.5(1.3-1.8)$ & 0.19 \\
\hline Split graft, $n(\%)(n=519)$ & $70(13)$ & $69 / 491(14)$ & $1 / 28(4)$ & 0.16 \\
\hline Live donor, $n(\%)(n=519)$ & $64(12)$ & $63 / 491(13)$ & $1 / 28(4)$ & 0.23 \\
\hline Cold ischemia time ${ }^{*}, h$, mean $\pm S D(n=517)$ & $5.5 \pm 2.9$ & $5.4 \pm 2.9$ & $7.1 \pm 2.8$ & 0.003 \\
\hline Organ from national source, $n / n(\%)(n=519)$ & $195(38)$ & $177 / 491(36)$ & $18 / 28(64)$ & 0.003 \\
\hline Red blood cells in operating room, units, median (IQR) $(n=519)$ & $2(0-6)$ & $2(0-5)$ & $8(4-13)$ & $<0.001$ \\
\hline Platelets in in operating room, units, median (IQR) $(n=519)$ & $0(0-5)$ & $0(0-4)$ & $5(2-10)$ & $<0.001$ \\
\hline
\end{tabular}

${ }^{*}$ Normal distribution. IQR Interquartile range

\section{REFERENCES}

1. Edwards EB, Harper AM. Application of a continuous disease severity score to the OPTN liver waiting list. Clin Transpl 2001:19-24.

2. Wiesner RH, Mcdiarmid SV, Kamath PS, et al. MELD and PELD: Application of survival models to liver allocation. Liver Transpl 2001; 7:567-80.

3. Bernardi M, Gitto S, Biselli M. The MELD score in patients awaiting liver transplant: Strengths and weaknesses. J Hepatol 2011;54:1297-306.

4. Wiesner R, Edwards E, Freeman R, et al. Model for End-stage Liver Disease (MELD) and allocation of donor livers. Gastroenterology 2003;124:91-6.

5. Sharma P, Schaubel DE, Gong Q, Guidinger M, Merion RM. End-stage liver disease candidates at the highest Model for End-stage Liver Disease scores have higher wait-list mortality than status-1A candidates. Hepatology 2012;55:192-8.

6. Shawcross DL, Austin MJ, Abeles RD, et al. The impact of organ dysfunction in cirrhosis: Survival at a cost? J Hepatol 2012;56:1054-62.

7. Alexopoulos S, Matsuoka L, Cho Y, et al. Outcomes after liver transplantation in patients achieving a Model for End-stage Liver Disease score of 40 or higher. Transplantation 2013;95:507-12.

8. Oberkofler CE, Dutkowski P, Stocker R, et al. Model for End-stage Liver Disease (MELD) score greater than 23 predicts length of stay in the ICU but not mortality in liver transplant recipients. Crit Care 2010;14:R117.

9. Von Elm E, Altman DG, Egger M, Pocock SJ, Gotzsche PC, Vandenbroucke JP. Strengthening the Reporting of Observational Studies in Epidemiology (STROBE) statement: Guidelines for reporting observational studies. BMJ 2007;335:806-8.

10. Moreau R, Jalan R, Gines P, et al. Acute-on-chronic liver failure is a distinct syndrome that develops in patients with acute decompensation of cirrhosis. Gastroenterology 2013;144:1426-37, e1-9.

11. Arvaniti V, D'amico G, Fede G, et al. Infections in patients with cirrhosis increase mortality four-fold and should be used in determining prognosis. Gastroenterology 2010;139:1246-56;56:e1-5.

12. Garcia-Tsao G, Sanyal A J, Grace ND, Carey W. Prevention and management of gastroesophageal varices and variceal hemorrhage in cirrhosis. Hepatology 2007;46:922-38.

13. Blei AT, Cordoba J. Hepatic encephalopathy. Am J Gastroenterol 2001;96:1968-76.

14. European Association for the Study of the Liver. EASL clinical practice guidelines on the management of ascites, spontaneous bacterial peritonitis, and hepatorenal syndrome in cirrhosis. J Hepatol 2010;53:397-417.

15. Machicao VI, Fallon MB. Hepatopulmonary syndrome. Semin Respir Crit Care Med 2012;33:11-6.

16. UNOS. MELD/PELD Calculator Documentation. <www.unos.org/ docs/MELD_PELD_Calculator_Documentation.pdf $>$ (Accessed February 11, 2015).
17. Massie AB, Caffo B, Gentry SE, et al. MELD exceptions and rates of waiting list outcomes. Am J Transplant 2011;11:2362-71.

18. Karvellas C J, Lescot T, Goldberg P, et al. Liver transplantation in the critically ill: A multicenter Canadian retrospective cohort study. Crit Care 2013;17:R28.

19. Feng S, Goodrich NP, Bragg-Gresham JL, et al. Characteristics associated with liver graft failure: The concept of a donor risk index. Am J Transplant 2006;6:783-90.

20. Singal AK, Hmoud BS, Guturu P, Kuo YF. Outcome after liver transplantation for cirrhosis due to alcohol and hepatitis C: Comparison to alcoholic cirrhosis and hepatitis $\mathrm{C}$ cirrhosis. J Clin Gastroenterol 2013;47:727-33.

21. Groenwold RH, Donders AR, Roes KC, Harrell FE Jr, Moons KG. Dealing with missing outcome data in randomized trials and observational studies. Am J Epidemiol 2012;175:210-7.

22. Doyle MB, Maynard E, Lin Y, et al. Outcomes with split liver transplantation are equivalent to those with whole organ transplantation. J Am Coll Surg 2013;217:102-12.

23. Ruiz R, Kunitake H, Wilkinson AH, et al. Long-term analysis of combined liver and kidney transplantation at a single center. Arch Surg 2006;141:735-41.

24. Sotil EU, Gottstein J, Ayala E, Randolph C, Blei AT. Impact of preoperative overt hepatic encephalopathy on neurocognitive function after liver transplantation. Liver Transpl 2009;15:184-92.

25. Kanwal F, Chen D, Ting L, et al. A model to predict the development of mental status changes of unclear cause after liver transplantation. Liver Transpl 2003;9:1312-9.

26. Fichet J, Mercier E, Genee O, et al. Prognosis and 1-year mortality of intensive care unit patients with severe hepatic encephalopathy. J Crit Care 2009;24:364-70.

27. Deberaldini M, Arcanjo AB, Melo E, et al. Hepatopulmonary syndrome: Morbidity and survival after liver transplantation. Transplant Proc 2008;40:3512-6.

28. Gupta S, Castel H, Rao RV, et al. Improved survival after liver transplantation in patients with hepatopulmonary syndrome. Am J Transplant 2010;10:354-63.

29. Arguedas MR, Abrams GA, Krowka MJ, Fallon MB. Prospective evaluation of outcomes and predictors of mortality in patients with hepatopulmonary syndrome undergoing liver transplantation. Hepatology 2003;37:192-7.

30. Schiffer E, Majno P, Mentha G, et al. Hepatopulmonary syndrome increases the postoperative mortality rate following liver transplantation: A prospective study in 90 patients. Am J Transplant 2006;6:1430-7.

31. Smith JO, Shiffman ML, Behnke M, et al. Incidence of prolonged length of stay after orthotopic liver transplantation and its influence on outcomes. Liver Transpl 2009;15:273-9. 


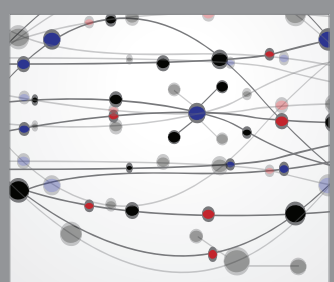

The Scientific World Journal
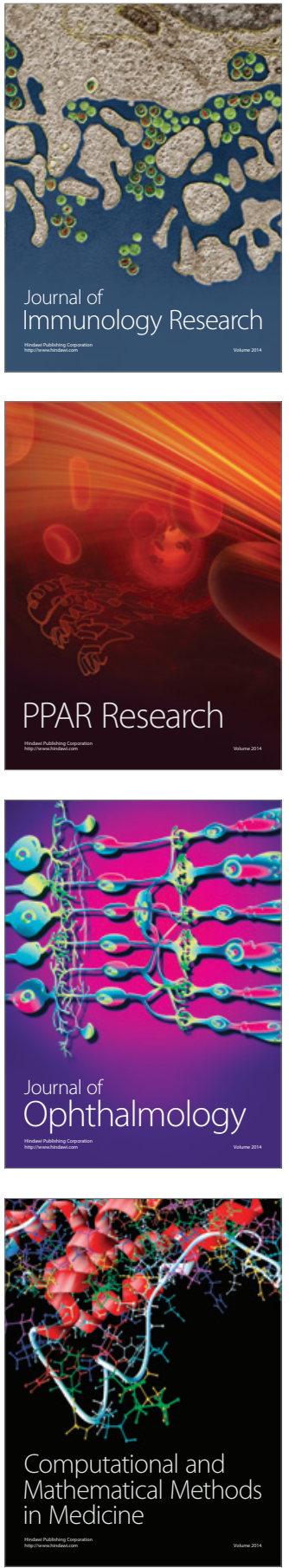

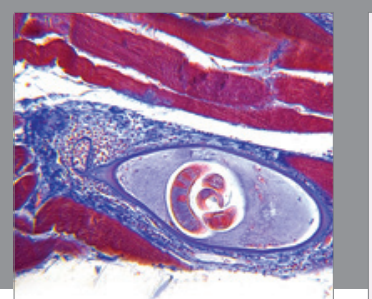

Gastroenterology Research and Practice

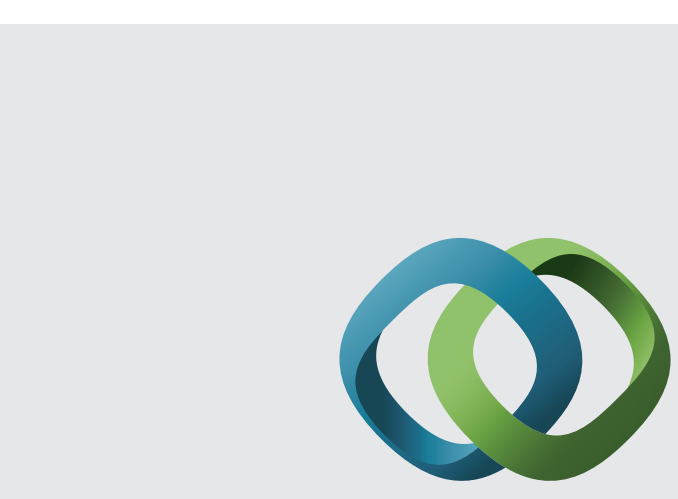

\section{Hindawi}

Submit your manuscripts at

http://www.hindawi.com
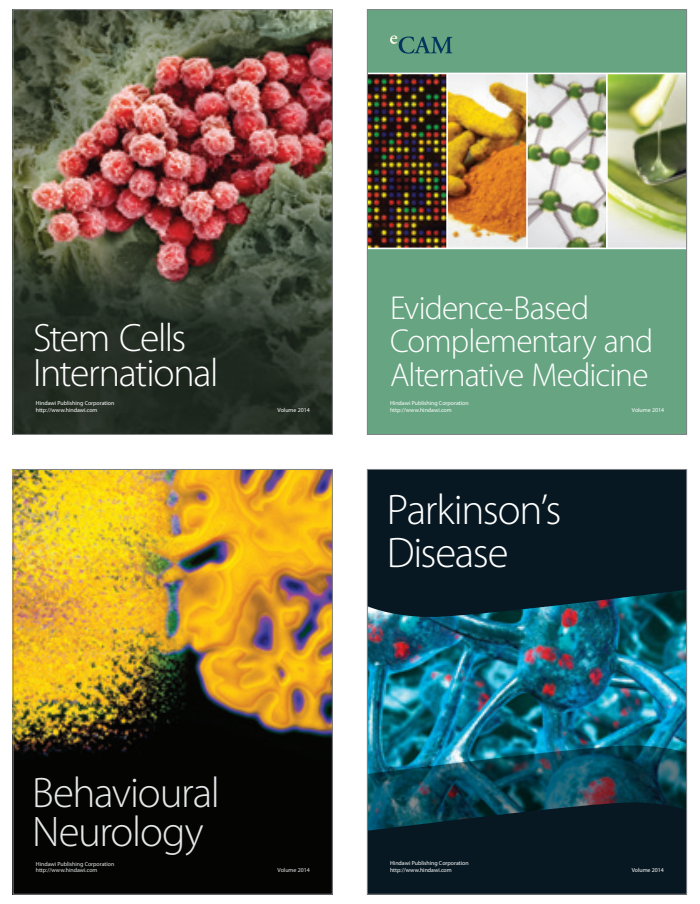
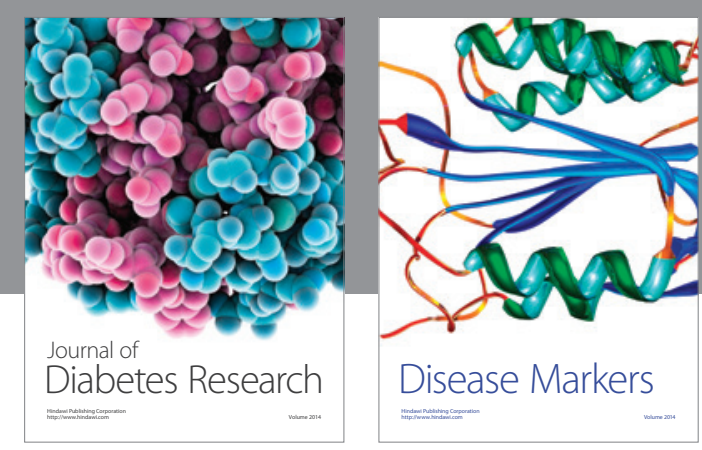

Disease Markers
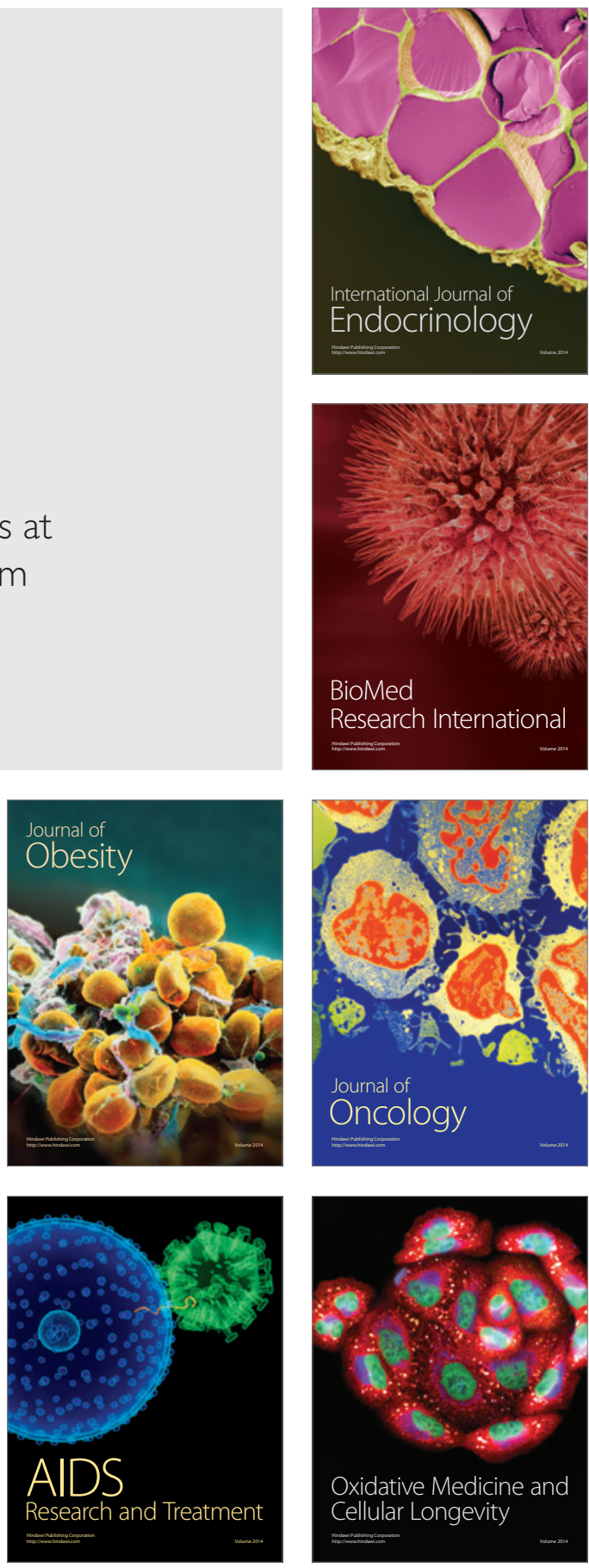